\title{
lettertotheeditor
}

\section{Minimum guidelines for the delivery of prenatal genetics services}

There has been an explosion of knowledge (human genetics) about the delivery of genetics services since Sarah Lawrence College offered the first Master's level genetic counseling program in 1969. Ironically, as the role of genetic testing in modern medical care grows, the number of trained genetic specialists will be insufficient to meet the demand. ${ }^{1}$ Likewise, there has been a proliferation of biotechnology companies marketing genetic testing services to nongeneticist physicians, even though only $19 \%$ of these companies believe that such physicians can adequately interpret genetic test results. ${ }^{2}$ Such beliefs are not intended to disparage the generalist or specialist whose patients need and request genetics services. Non-genetic physicians themselves report a need for more training., ${ }^{3,4}$

In 1995, Garber and Hixon stated that "pregnant patients with concerns about the well-being of their fetuses represent the largest group requiring genetic counseling services." This, combined with the ever increasing understanding of the human genome, only points to the need to establish minimal guidelines for the delivery of prenatal genetics services. Such guidelines would not only serve as an assessment tool for those providing prenatal genetics services, the guidelines help those seeking services to determine the quality and standards that they are receiving. However, developing such guidelines and ensuring voluntary acceptance is no easy task. Guidelines for the appropriate use of genetic tests are currently being developed by both governmental agencies and specialty organizations. ${ }^{6}$ Often such guidelines are specific to one condition, impossible for the general physicians to implement, and even more cumbersome for the consumer of prenatal services. ${ }^{7-9}$

On the one hand, there seems to be a rush to develop guidelines for any number of medical tests and services. On the other hand, no one organization or body can "enforce" the standards established by the guidelines. Previously, the Great Lakes Regional Genetics Group (GLARGG) has developed guidelines as an ongoing effort of the Evaluation of Clinical Genetics Services Subcommittee to provide assessment of clinical genetics units in our six state region: Illinois, Indiana, Michigan, Minnesota, Ohio, and Wisconsin. The first set of guidelines, "Minimum Guidelines for the Delivery of Clinical Genetics Services," has been used to evaluate centers within this region. ${ }^{10}$ Each center participates in the evaluation process on a voluntary basis. The on-site evaluations are done by a volunteer peer and/or consumer reviewer from another state.

The same subcommittee has developed a parallel set of minimum guidelines for the Delivery of Prenatal Clinical Genetics
Services. These guidelines have been developed by a broad range of genetics professionals and consumers, and are published with the hope that they will stimulate discussion on the need for comprehensive evaluation of prenatal genetics services. We hope they will serve as the basis for developing nationwide standards that promote quality assurance of prenatal clinical genetics services that are understandable and useful to the professional and consumer alike.

GLARGG and its membership welcome and encourage comments about these guidelines and about the wisdom of undertaking quality assurance of prenatal genetics services. Quality assurance guidelines would affect a variety of entities that provide prenatal genetics services: A subsection of a section, a section or division within a department, a department within a school, or a private institution, office, or agency. The guidelines published below are general recommendations for the practice and provision of prenatal clinical genetics services, and while they are intended to promote quality of services along with respect for and collaboration with the patient and family, meeting them does not necessarily assure a good quality of care or a positive patient/family experience or outcome. The following guidelines must be met when providing prenatal genetics services.

1. An American Board of Medical Genetics certified or eligible MD or PhD clinical geneticist or an American Board of Genetic Counseling certified or eligible genetic counselor is available for consultation or case review.

2. An American Board of Medical Genetics certified or eligible $\mathrm{MD}$ or $\mathrm{PhD}$ clinical geneticist or an American Board of Genetic Counseling certified or eligible genetic counselor supervises non-board certified or non-board eligible counselors.

3. Support services are available to patients and their families including genetic counselors, social workers, nurses, psychologists, perinatologists, and other experts.

4. Patient/family privacy during evaluations and all counseling sessions is strictly maintained.

5. Considering the fetus of the pregnant female as the index patient, a three generation family pedigree or family history questionnaire is completed and analyzed for every patient.

6. Genetic counseling is provided whenever a prenatal testing procedure is performed.

7. Only cytogenetic results provided by a cytogenetics laboratory certified by the College of American Pathologists are accepted.

8. Written records on all evaluations, counseling sessions, and educational information on testing should be provided to all patients or families, including:

- Separate, informed consent forms for any procedure performed such as aminocentesis, chorionic villus sampling (CVS), or percutaneous umbilical blood sampling (PUBS); - Educational information such as pamphlets or brochures, 
videotapes, or other media on the procedure prior to the performance of the procedure;

- Summary of the procedure being performed including follow-up, emergency procedures, and accuracy rates of the test;

- Follow-up letter reviewing the test results, information presented, and counseling provided should be sent to the patient; and

- Letter indicating that a patient has received services should be sent to the referring physician.

9. Medical information and/or records should be released only after receipt of written permission from the patient or parents.

10. At an appropriate time following the provision of services to a patient/family, the medical/counseling record should be reviewed. Criteria for the review of the patient's record should be established in writing, and chart deficiencies or problems discovered during the evaluation or follow-up of the patient/family should be promptly corrected.

11. A system for handling patient and staff complaints should exist. Complaints should be reviewed at least six times a year, and appropriate decisions should be made about the complaints.

12. A mechanism that ensures adequate follow-up on the evaluation and testing that has been done on patients should exist.

\section{Acknowledgement}

This project was supported by a Region V grant from the Maternal and Child Health Bureau, Public Health Service, U.S. Department of Health \& Human Services.

The Evaluation of Clinical Services Subcommittee, Great Lakes Regional Genetics Group:

Annemarie Sommer, MD

The Ohio State University College of Medicine Children's Hospital Columbus, Ohio

Mark Lubinsky, MD Genetics Division Children's Hospital of Wisconsin Department of Pediatrics Medical College of Wisconsin Milwaukee, Wisconsin

Michelle Cichon, MS Oakwood Hospital Dearborn, Michigan
Nanette N.S. Gilpin, MD

Department of Pediatrics

Christie Clinic Assoc.

Champaign, Illinois

David D. Weaver, MD

Department of Medical and Molecular Genetics Indiana University Medical Center

Indianapolis, Indiana

Mary Jarvis Ahrens, MS

Fairview-University Medical Center

Minneapolis, Minnesota

Vicki L. Matthias Hagen, MS

Fairview-University Medical Center Minneapolis, Minnesota

Peggy Mann Rinehart

Alliance of Genetic Support Groups Division of General Pediatrics and Adolescent Health

University of Minnesota

Minneapolis, Minnesota

\section{References}

1. Holtzman NA. Primary care physicians as providers of front-line genetics services. Fetal Diagn Ther 1993;8(Suppl 1):213-219.

2. Holtzman NA, Hilgartner $S$, Brierley-Bowers K, et al. Survey of biotechnology companies (BTCs) and molecular and cytogenics laboratories (LABs) on genetic testing. Am I Human Genet 1995;57(Suppl):A3.

3. Collins FC. Lots of mutations, lots of dilemmas. New Engl J Med 1996;334:186-188

4. Hayflick SI, Eiff MP, Carpenter L, Steinberger J. Primary care physicians' utilization and perceptions of genetics services. Genetics In Medicine 1998;1(1):13-21.

5. Garber A, Hixon H. Prenatal genetic counseling. Clin Perinatol 1995;17:749-759.

6. National Institutes of Health-Department of Energy Working Group on the Ethical, Legal \& Social Implications of Human Genome Research. Interim Principles of the Task Force on Genetic Testing. March 1996. [http://infonet.welch.jhu.edu/policy/genetics/]

7. American Society of Human Genetics. American Society of Human Genetics Statement on Cystic Fibrosis Screening. Am J Hum Genet 1990;46:393.

8. American Society of Human Genetics. Statement of the American Society of Human Genetics on Cystic Fibrosis Carrier Screening. A m J Hum Gen 1992;51:1443-1444.

9. American Society of Human Genetics. Statement of the American Society of Human Genetics on Genetic Testing for Breast and Ovarian Cancer Disposition. Am I Hum Genet 1994;55:1-iv.

10. Weaver D, Baker D, Theobuld M, Cohen F, King R, Krueger S, Laxova R, Lubinsky M. Minimum guidelines for the delivery of clinical genetics services. Am I Hum Genet 1993:53:287-289.

Editor's Note:

The clinical services subcommittee of one of the $\mathrm{MCH}$ supported regional genetics groups has submitted this letter of recommendations for minimum guidelines in the delivery of prenatal genetics services. The Editors feel that this should stimulate discussion of this topic and invite responses to these guidelines. 